\title{
Evaluation of effect changing temperature on lamb-wave based structural health monitoring
}

Sattar MOHAMMADI ESFARJANI

DOI: 10.30464/jmee.2019.3.4.329

Cite this article as:

Mohammadi Esfarjani S. Evaluation of effect changing temperature on lamb-wave based structural health monitoring. Journal of Mechanical and Energy Engineering, Vol. 3(43), No. 4, 2019, pp. 329-336.

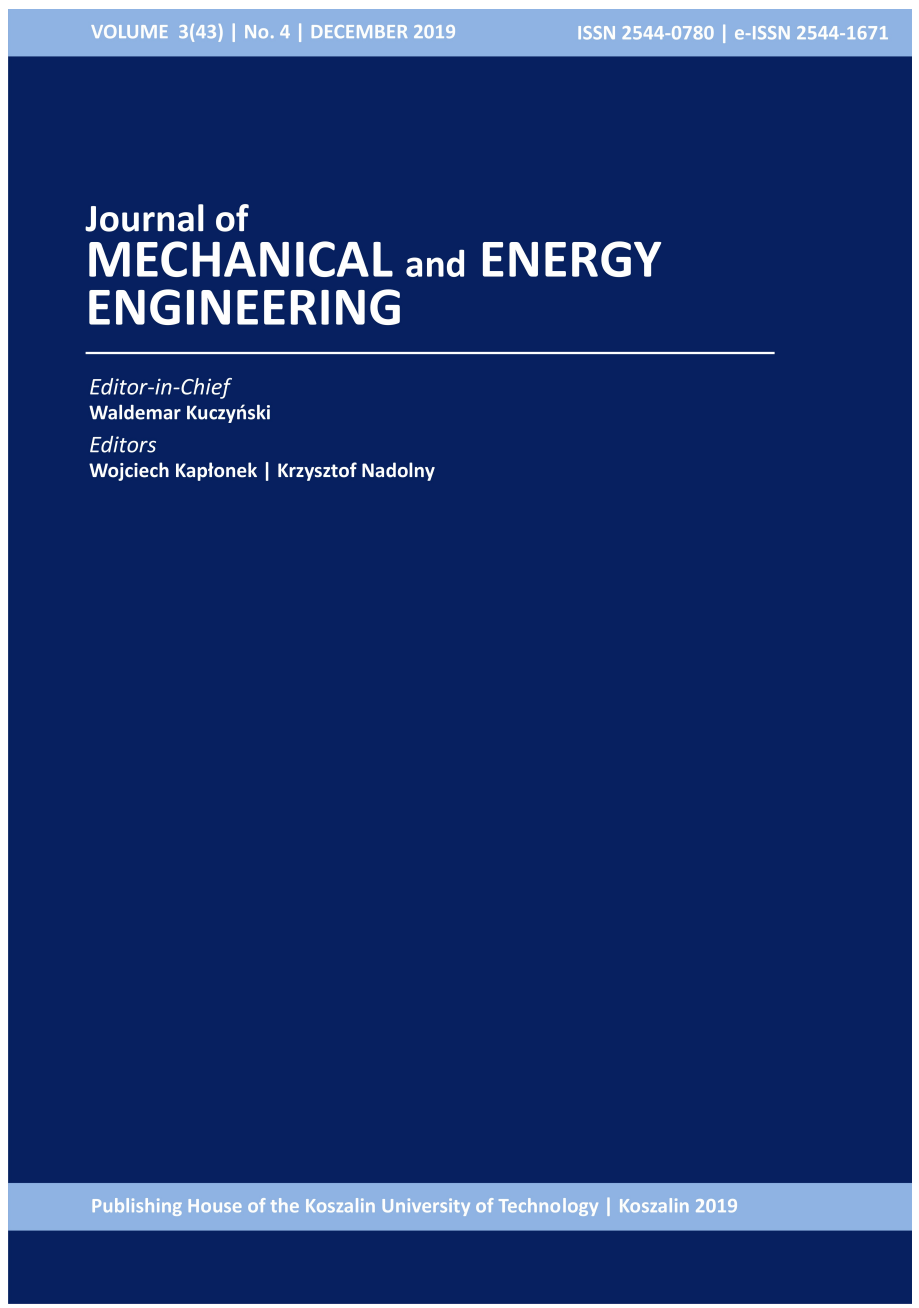

Journal of Mechanical and Energy Engineering

Website: jmee.tu.koszalin.pl

ISSN (Print): 2544-0780

ISSN (Online): 2544-1671

Volume: $3(43)$

Number: 4

Year: 2019

Pages: $329-336$

Article Info:

Received 14 December 2019

Accepted 14 January 2020

\section{Open Access}

This article is distributed under the terms of the Creative Commons Attribution 4.0 (CC BY 4.0) International License (http://creativecommons.org/licenses/by/4.0/), which permits unrestricted use, distribution, and reproduction in any medium, provided you give appropriate credit to the original author(s) and the source, provide a link to the Creative Commons license, and indicate if changes were made. 


\title{
EVALUATION OF EFFECT CHANGING TEMPERATURE ON LAMB-WAVE BASED STRUCTURAL HEALTH MONITORING
}

\author{
Sattar MOHAMMADI ESFARJANI ${ }^{*}$ \\ ${ }^{1 *}$ Department of Mechanical Engineering, Najafabad Branch, Islamic Azad University, Najafabad, Iran \\ (satar.iran@gmail.com)
}

(Received 14 December 2019, Accepted 14 January 2020)

\begin{abstract}
The purpose of this paper is to investigate the effect of temperature change on the Lamb wave-based SHM method. This study evaluates the Lamb wave method's ability to detect damage to an AL2024-T3 sheet, assessed by a near-surface hole. Lamb waves are created via numerical simulation with the commercial Finite Element (FE) package ABAQUS. In this study, the Lamb wave-based SHM method using displacement responses is used. The results indicate that this method is able to detect a near-surface hole in the AL2024-T3 sheet as well as its location, with close approximation. Subsequently, the AL1100 sheet was investigated for changes in temperature from this method, which was evaluated over a temperature range of $-200^{\circ} \mathrm{C}$ to $204^{\circ} \mathrm{C}$. The results show that temperature change in the range of $-200^{\circ} \mathrm{C}$ to $93^{\circ} \mathrm{C}$ has no effect on the displacement responses. However, the graphs related to temperature change of more than $149^{\circ} \mathrm{C}$ do not overlap with the reference temperature. Hence, it has been concluded that Lamb waves can be used as an SHM method in the temperature range of $-200^{\circ} \mathrm{C}$ to $93^{\circ} \mathrm{C}$ without having to worry about the effects of temperature change on the results.
\end{abstract}

Keywords: structural health monitoring; lamb wave, temperature; AL2024-T3 sheet; AL1100 sheet.

\section{INTRODUCTION}

The safety is extremely important in aviation industry. Any defect in aircraft structures is not acceptable due to the possibility of loss of life and capital involved. Conditions sustaining such as; high loads, fatigue cycles and extreme temperature differentials can cause defect in aircraft structures. Inspection of aircraft, play a very important role in aviation safety [1-3]. Non-destructive testing (NDT) methods are used to ensure the safe operation of aircraft structures. Ultrasonic Testing (UT) is one of commonly used methods for NDT. UT is used to detect the presence of defects of the materials and for analyze and characterize some important properties of materials such as microstructure, mechanical properties of materials [4-6]. Lamb waves are ultrasonic waves in thin plates [7]. Lamb waves are guided acoustic waves which propagate in the plane of a plate and, like bulk acoustic waves, their interaction with defects means that they can be used for inspection purposes [8]. In recent years, lamb wave based damage detection has been widely investigated. Larger area scanning, low attenuation, easy implementation using piezoelectric (PZT) transducers, online Structural Health Monitoring (SHM) are some of several advantages of lamb wave based technique $[9,10]$.

In recent years, the use of simulation models to develop ultrasonic based damage detection techniques has become very popular, because it's a less expensive and time-consuming procedure than real structures or experimental models [11, 12]. Also, experimental setup is also a fairly difficult process. Since the Finite Element Method (FEM) has been widely accepted as an analysis tool in SHM the above mentioned constraints can be overcome by using a validated FE model to simulate the real structure [13]. The FEM is the best method when complex damage, geometry or boundary is involved. A transient dynamic FE simulation of lamb wave with piezoelectric transducers for damage detection in a composite plate 
is carried out by Wenzhong and $\mathrm{Li}$ [14] and they demonstrated that the numerical simulation is the effectiveness of the approach [14]. Nieuwenhuis et al [15], presented two-dimensional FEM transient simulations of the source region, we show how those results can guide a designer in choosing transducer dimensions for mode selectivity [15]. In this study, a transient dynamic FE simulation of lamb wave for damage detection in 2024-T3 aluminum sheet is carried out. The FE analysis was conducted using the commercial FE package ABAQUS. In this study, the Lamb wave-based SHM method using displacement responses is used. To use lamb wave based SHM, it's necessary to consider the effect of environmental factors such as changing temperature on the lamb waves. Several researches on changing temperature on UT technique have been done. Most of previous researches have been experimentally $[4,16]$. One of the earliest works on the temperature effects on Lamb wave signals was performed by Francesco Lanza di Scaleaa and Salvatore Salamone [17]. The model is used to predict the S0 and A0 response spectra in aluminum plates for the temperature range of -40 to $+60^{\circ} \mathrm{C}$. The study shows substantial changes in lamb wave amplitude response caused solely by temperature excursions [17]. A pitch-catch arrangement between 50 and $150 \mathrm{kHz}$ on sandwich panels at low temperatures $-90^{\circ} \mathrm{C}$ ) was performed by Blaise and Chang [18]. The authors observed a decrease in wave amplitude and time of flight from ambient temperature to $-90^{\circ} \mathrm{C}$, and they developed an empirical model to fit the experimental data [13]. Konstantinidis et al. [19] studied the variation in wave amplitude between 22 and $32^{\circ} \mathrm{C}$ for various portions of lamb wave measurements in aluminum plates and showed that temperature changes result in shifts in wave arrival times and in center frequency of the received waves under constant excitation frequency. $\mathrm{Lu}$ and Michaels (2005) and Michaels and Michaels (2005) studied the difference in various damage-sensitive features of diffuse lamb wave signals at temperatures varying between 5 and $40^{\circ} \mathrm{C}$, and showed that a changing time of flight, which was attributed to thermal expansion and Young's modulus of the substrate. [20, 21] Temperature.compensation.of.guided.wave.based.supe rvised.SHM.systems.is.compulsory for components exposed to environmental conditions by DAN et al. [22]. They showed that the wave variables are transferred from the wave coefficients, the shear and longitudinal velocities [22]. Han et al. [23] studied FE Analysis of lamb wave propagation in a thin aluminum plate..Simulations of isothermal tests are conducted over a temperature range of $0-190^{\circ} \mathrm{F}$ using 100 and $300 \mathrm{kHz}$ as excitation frequencies.. They showed that elevated temperatures delay the Lamb wave propagation, although the delays are found to be minimal at the temperatures tested [23]. Dhutti et al
[24], studied application of Ultrasonic Guided Wave (UGW) technique for in-service SHM of high temperature (HT) pipework. They settled the system on a pipe operating at up to $200^{\circ} \mathrm{C}$ for over 1 year [24].

The purpose of the study is to evaluate effect of changing temperature on SHM using lamb waves. For this propose, sensitivity analysis of the lamb wave to temperature changes range of $-200^{\circ} \mathrm{C}$ to $204^{\circ} \mathrm{C}$ in $\mathrm{AL}$ 1100 sheet is evaluated. A assuming that the location of inspection is located at the hottest and coldest places on Earth, and that we want to inspect a component at these places, then $-70^{\circ} \mathrm{C}$ to $+70^{\circ} \mathrm{C}$ change in the temperature range is enough to investigate the effect of changes in the temperature on the lamb wave. However, in this paper, a greater temperature range was selected to achieve wider and more accurate judgments about the effect of changes in the temperature on the lamb wave. In this study, to evaluate the ability of lamb waves based SHM method and effect of changing temperature on SHM using lamb waves; two different types of aluminum (1100 and 2024-T3) are used. SHM to assess the structural condition plays a vital role for safe and efficient operation of aircraft. 2024-T3 aluminum sheet is widely used in the aviation industry. Thus, in this study, to evaluate the ability of the lamb wave-based SHM method, a 2024-T3 aluminum sheet is selected. To evaluate the sensitivity analysis of the lamb waves to temperature changes, an AL 1100 sheet is selected, because it has a high coefficient of thermal expansion. The remainder of the paper is organized into four sections: In Section II, effect change temperature on mechanical properties will be discussed. Numerical simulation is presented in Section III. The conclusion is reported in Section IV.

\section{THEORY EFFECT OF CHANGING TEMPERATURE ON LAMB WAVE}

Particularly, solids experience upon change of temperature, modifications in their mechanical properties, of interest being here the elastic and shear moduli and the density, which, at their turn cause changes in the two main acoustic properties of any given material, acoustical absorption and speed of sound [25].

\subsection{Wave propagation}

Andrews 2007, indicate that plate waves are result from the conversion between transverse $(T)$ and longitudinal $(L)$ modes. Wave propagation is dependent on the density $(\rho)$ and elastic properties of a medium. The longitudinal wave speed is characterized by the Young's modulus $(E)$ as [18]:

$$
c_{L}=\sqrt{(E / \rho)} .
$$


Similarly, the transverse shear wave speed is characterized by the shear modulus $(G)$ as [18]:

$$
c_{T}=\sqrt{(G / \rho)} .
$$

\subsection{Effect of changing temperature on} mechanical properties of sample

$\mathrm{Xu}$ and Zhishen showed that the changes caused by temperature were analyzed based on the following aspects: (1) change of the passion rate of the aluminum alloy; (2) changes of the elastic modulus of the aluminum alloy. Scalea and Salamone indicate that a linear dependence of each property on temperature is assumed as following equation (3) [26]:

$$
P(T)=P\left(T_{0}\right)+\frac{\partial P(T)}{\partial T} \Delta T,
$$

where $P$ represents one of the mechanical.properties of sample, such as Young's modulus E, Poisson's Ratio $v$, shear modulus $G$, and bulk modulus $K, T$ is the generic temperature, $T_{0}$ is the ambient temperature $20^{\circ} \mathrm{C}$, and $\frac{\partial \mathrm{P}(\mathrm{T})}{\partial \mathrm{T}}$ is the sensitivity to temperature [19]. Also, Nowacki (1962) has demonstrated that the temperature dependence of the modulus of elasticity for most of engineering materials is given [27]:

$$
E(T)=E_{0}(1-\gamma T),
$$

where $E_{0}$ is the value of Young's modulus at the reference temperature, i.e. $T=0$, and $\gamma$ is the slope of the variation of $E$ with $T$ [27].

\section{DAMAGE DETECTION USING LAMB WAVE}

In this section, which first evaluates the ability of the damage detection of lamb waves, a 2024-T3 aluminum alloy sheet with a lamination defect is assessed. Aluminum alloys are widely used for aerospace applications including primary aircraft structures because of lightweight or corrosion resistance is required. The 2024-T3 aluminum sheet is one of the best known high-strength aluminum alloys. It is thought of as the aircraft alloy because of its strength. It has excellent fatigue resistance. Typical uses for 2024-T3 aluminum sheet are aircraft skins, cowls, aircraft structures. Alloy 2024-T3 sheet products are used extensively in commercial and military aircraft for fuselage skins, pressure cabin skins, wing skins and engine areas where elevated temperatures to $250^{\circ} \mathrm{F}\left(121^{\circ} \mathrm{C}\right)$ are often encountered [28]. Then the sensitivity analysis of the lamb waves to temperature changes in an $\mathrm{AL} 1100$ sheet is evaluated. Lamb waves are created via numerical simulation with the commercial FE package ABAQUS. The displacement responses of nodes are obtained.

\subsection{Simulation modelling and analysis of intact structure}

First, a FE model of the 2024-T3 aluminum alloy sheet is created using ABAQUS. A 2024-T3 aluminum alloy sheet with a near-surface defect (a hole) is shown in Figure 1. The material properties are listed in Table 1. In an experimental test, data are obtained from sender and receiver sensors. In a simulation test, two nodes are determined on the surface of the plate as sender and receiver sensors. The locations of the sender and receiver sensors are shown in Figure 2. Multiple runs show that the type of mesh has a non-significant effect on the results, while free meshing is more suitable on the damaged section. Thus, free meshing with triangular and tetrahedral elements is utilized (Figure 3). Then lamb waves are created and the displacement responses of the receiver node are obtained for an intact structure (Figure 4). The result of using the lamb wave for an intact structure is shown in Figure 5.

a)

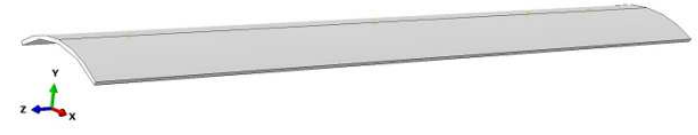

b)

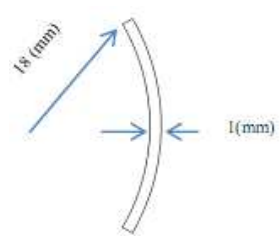

Fig. 1. a) \& b) A FE model of beam was created using ABAQUS.4

Tab. 1. Material properties for 2024-T3 aluminium alloy

\begin{tabular}{lc}
\hline Material & 2024-T3 aluminium alloy \\
\hline Density $(\rho) .(\mathrm{g} / \mathrm{cc})$ & 2.7 \\
\hline Poisson's Ratio $(\mathrm{v})$ & 0.33 \\
\hline $\begin{array}{l}\text { Modulus of Elasticity }(\mathrm{E}) \\
\text { (Gpa) }\end{array}$ & 70 \\
\hline
\end{tabular}

(Gpa)

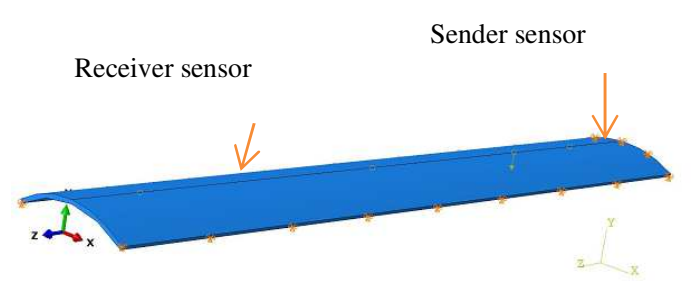

Fig. 2. The location of sender and receiver sensors 


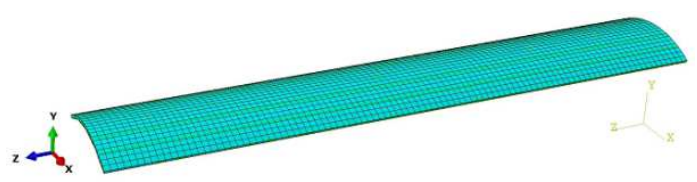

Fig. 3. Free meshing technique with linear tetrahedral and hexahedral elements

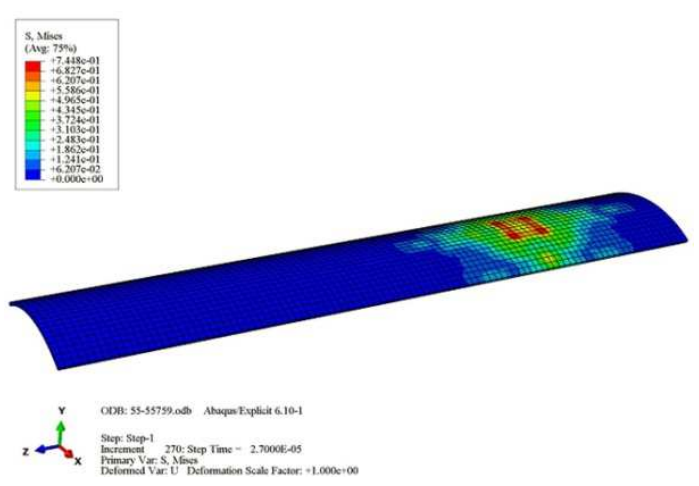

Fig. 4. Lamb wave are created in $\mathrm{Al} 2024-\mathrm{T} 3$ sheet in ABAQUS



Fig. 5. SHM of intact AL2024-T3 sheet using lamb wave

\subsection{Simulation modelling and analysis of damaged structure}

First, a hole defect is created in the near-surface of the model. The type of defect is a hole with $0.1 \mathrm{~mm}$ diameter. The size of the defect is shown in Figure 6. The elements of type, the total number of elements and nodes for the undamaged model and damage scenarios that were created in the model are shown in Table 2. Then, lamb waves are created and the displacement responses of receiver node are obtained for the damaged structure. The result of using the lamb wave for the intact structure is shown in Figure 7.

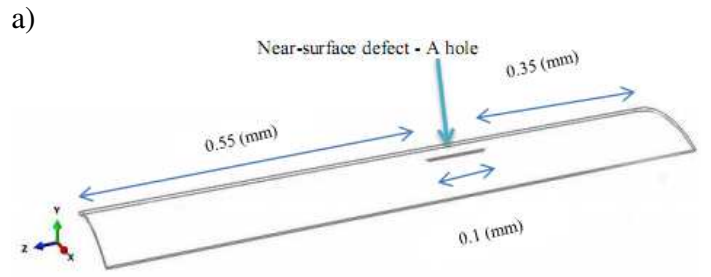

b)

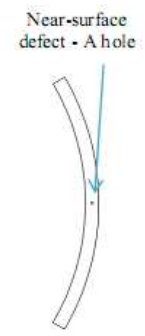

Fig. 6. A defect was created in model

Tab. 2. The elements of type, the total number of elements and nodes for undamaged model and damage scenario that was

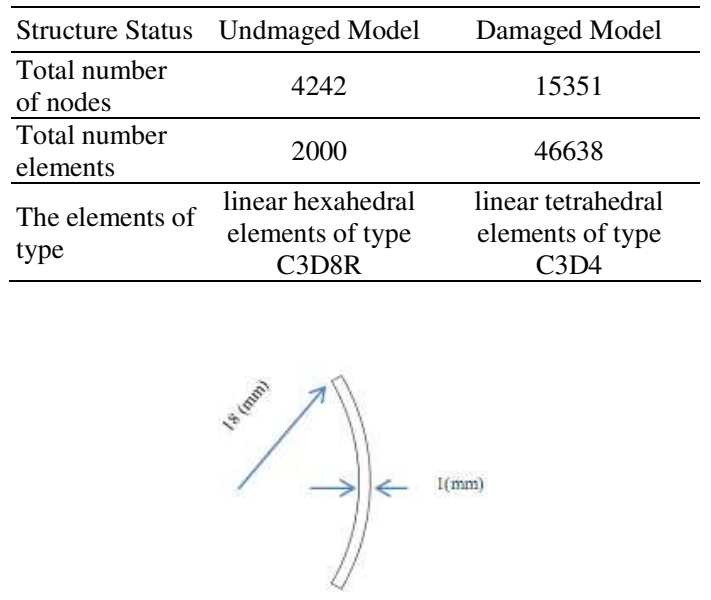

Fig. 7. A FE model of beam was created using ABAQUS.4

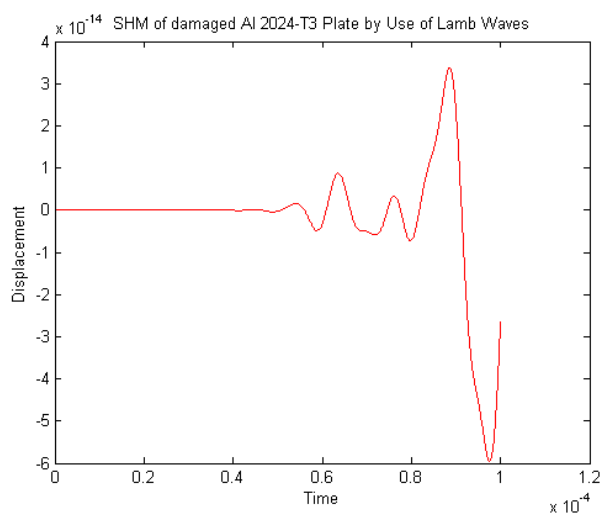

Fig. 8. SHM of damaged AL2024-T3 sheet using lamb wave 


\subsection{Result and discussions of damage detection using the lamb wave}

As shown in Figurs 5 and 7, the shape of the wave propagation process of the intact structure is different from the damaged structure. The wave propagation process of the intact structure is more regular. With the damaged structure, the wave propagation process is more irregular than with the intact structure. Also, the lamb wave in the intact structure is more powerful than in the damaged structure (Figure 8). These differences will lead to identifying damage. As seen in Figure 8 , the lamb wave is able to detect a nearsurface hole in an AL2024-T3 sheet.

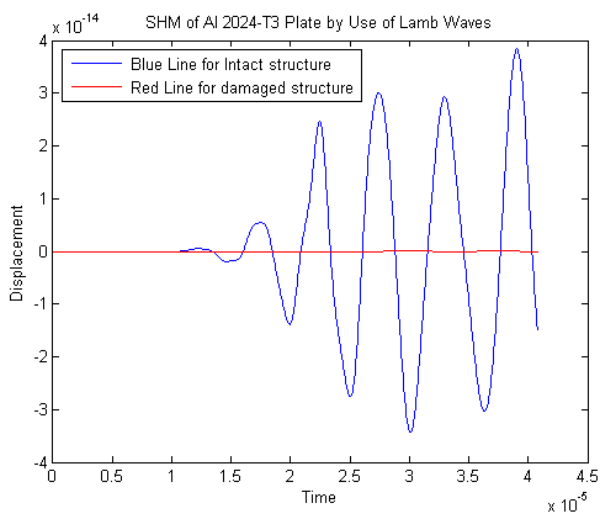

Fig. 9. Compare SHM for intact and damaged AL2024-T3 sheet using lamb wave

\subsection{Effect of the temperature on the lamb wave}

In this section, sensitivity analysis of the lamb wave to temperature changes in $\mathrm{AL} 1100$ sheet is evaluated. Aluminum 1100 is one of the most widely used alloys, with excellent forming properties in annealed states and may be suitable for bending, spinning, drawing, stamping, roll forming, and many other applications. Typical applications include chemical storage, processing equipment, kitchen utensils, and general sheet metal work. The material properties are listed in Table 3. As shown in Figure 9, to evaluate the effect of changing temperature on lamb waves, the results of analysis of an intact structure obtained by the lamb wave method at a temperature of $21^{\circ} \mathrm{C}$ are selected as the reference temperature and initial situation $\left(D_{L W, j}^{i}\right)$ for the inspection process.Then, the intact structure is evaluated in a temperature range of $-200^{\circ} \mathrm{C}$ to $204^{\circ} \mathrm{C}$. The analysis results of an intact structure obtained by the Lamb wave method in a temperature range of $-200^{\circ} \mathrm{C}$ to $204^{\circ} \mathrm{C}$ are selected as the secondary status $\left(D_{L W, j}^{S}\right)$.for the inspection process. The lamb wave method is not sensitive to temperature change, if the results of should have overlap; otherwise, it is sensitive to temperature change. The displacement responses of intact structure are obtained via numerical simulation with the commercial FE package ABAQUS. The results of the investigation into the Lamb wave under temperature changes between $-200^{\circ} \mathrm{C}$ and $203^{\circ} \mathrm{C}$ is shown in Figure 10. The figure shows that the graphs are almost overlapping for the range of $-200^{\circ} \mathrm{C}$ to $93^{\circ} \mathrm{C}$. In other words, temperature changes in the range of $-200^{\circ} \mathrm{C}$ to $93^{\circ} \mathrm{C}$ had no effect on the response of displacement. However, the graphs relating to temperature changes of more than $149^{\circ} \mathrm{C}$ do not overlap with the reference temperature. It was been found that lamb waves can be used as an SHM method in the temperature range of $-200^{\circ} \mathrm{C}$ to $93^{\circ} \mathrm{C}$, without having to worry about the effects of temperature changes on our results.

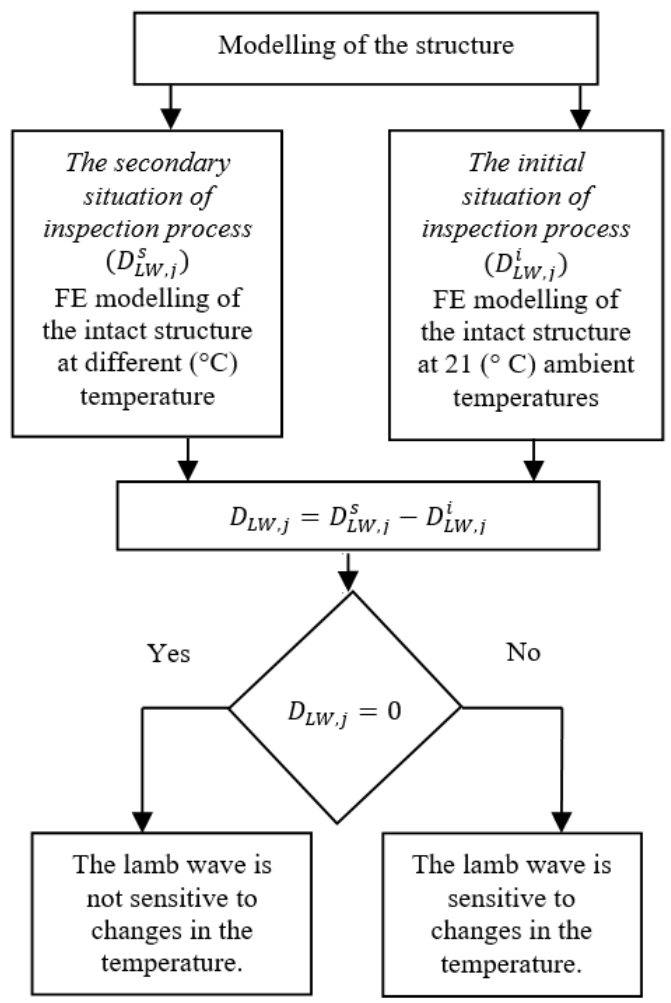

Fig. 10. Flowchart of the method used to investigate temperature changes effect on the lamb wave method

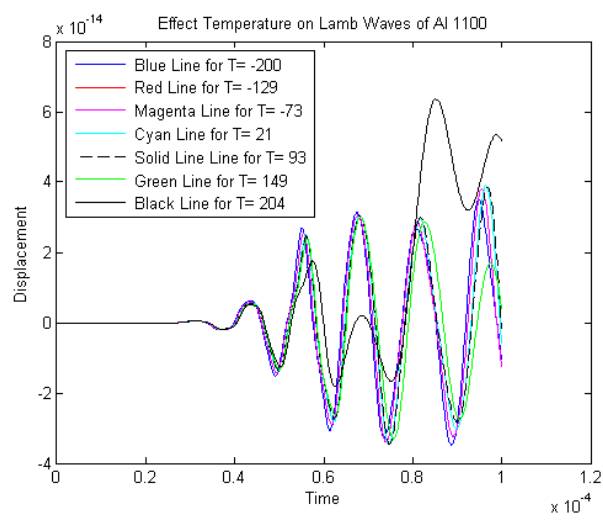

Fig. 11. Effect changing temperature on the lamb wave under changes temperature range of $-200^{\circ} \mathrm{C}$ to $204^{\circ} \mathrm{C}$ 
Tab. 3. Material properties for aluminium 1100

\begin{tabular}{lc}
\hline Material & Aluminium 1100 \\
\hline Density $(\rho) \cdot(\mathrm{g} / \mathrm{cc})$ & 2.71 \\
\hline Poisson's Ratio $(v)$ & 0.33 \\
\hline $\begin{array}{l}\text { Modulus of Elasticity }(E) \\
(\mathrm{Gpa})\end{array}$ & 70 \\
\hline
\end{tabular}

\section{CONCLUSIONS}

In this paper, effects of temperature on SHM using lamb waves in AL2024-T3 plate were investigated. In this study, the evaluation of effect changing temperature on lamb-wave based SHM using the displacement responses of nodes is used. This study evaluates the Lamb waves method's ability to detect damage to an AL2024-T3 sheet, assessed by a nearsurface hole. Lamb waves were created via numerical simulation with the commercial FE package ABAQUS. The.results.indicate.that the IPV method is able to detect a near-surface hole.in.the AL2024-T3 sheet as.well.as.its.location, with.close approximation. An AL 1100 sheet was investigated for the effect of changes in temperature on the lamb waves based SHM method, evaluated over a temperature range of $-200^{\circ} \mathrm{C}$ to $204^{\circ} \mathrm{C}$. The results show that temperature changes don't effect on displacement responses, thus neither are SHM analysis results affected by temperature changes. In other word, the Lamb waves are not sensitive to changes in temperature range of $-200^{\circ} \mathrm{C}$ to $204^{\circ} \mathrm{C}$. This study highlighted the importance of applying simulation methods to develop NonDestructive Testing (NDT) techniques, especially for evaluation the effect changes in environmental temperature.

\section{Nomenclature}

Symbols

E $\quad-$ Young's modulus

$K \quad$ - bulk modulus

$P \quad-$ mechanical.properties

$T \quad-$ generic temperature

$c_{L} \quad$ - longitudinal wave

$c_{T} \quad-$ transverse shear

$T_{0} \quad$ - ambient temperature

$v \quad$ - Poisson's Ratio

$\frac{\partial P(T)}{\partial T}-$ sensitivity to temperature

\section{Greek letters}

$$
\begin{array}{ll}
\rho & - \text { density } \\
\gamma & - \text { slope of the variation }
\end{array}
$$

\section{Acronyms}

HT - High Temperature

UT - Ultrasonic Testing

FEM - Finite Element Method

NDT - Non-destructive testing

SHM - Structural Health Monitoring

UGW - Ultrasonic Guided Wave

\section{References}

1. Bar-Cohen Y., Mal A. K., Lih S-S., Chang Z. (1999). Composite materials stiffness determination and defects characterization using enhanced leaky Lamb wave dispersion data acquisition method. Proc. SPIE 3586, Nondestructive Evaluation of Aging Aircraft, Airports, and Aerospace Hardware III, CA, USA. DOI: $10.1117 / 12.339892$

2. Liao M. (2019). Review of Aeronautical Fatigue and Structural Integrity Work in Canada (2017 - 2019). International Committee on Aeronautical Fatigue and Structural Integrity (ICAF), Report No.: LTR-SMM2019-0063, Available at (October 2019): http://www.icaf2019.org/confdata/icaf2019/files/Raporty\%20Delegat\%C3\%B3w/Cana dian\%20National\%20Review\%202019.pdf

3. Keulen C.J., Rocha B., Yildiz M., Suleman A. (2014)..Structural Health Monitoring Using Lamb Wave Based.Piezoelectric Networks and Phased Array Solutions. STO-EN-AVT-220: Structural Health Monitoring of Military Vehicles, EN-AVT-220-09. DOI: 10.14339/STO-EN-AVT-220.

4. Thanh P. V., Nhung P. T.T., Thuy L. T. M., Nhai N. H. (2015). Effect of Temperature on Ultrasonic Velocities, Attenuations, Reflection and Transmission Coefficients between Motor Oil and Carbon Steel Estimated by Pulseecho Technique of Ultrasonic Testing Method. VNU Journal of Science: Mathematics - Physics, Vol. 31, No. 4, pp. 39-48.

5. Mohammadi Esfarjani S., Salehi M. (2017). Optimization the inner product vector method and its application to structural health monitoring. Journal of Vibroengineering, Vol. 19, No. 4, pp. 2578-2585..DOI: 10.21595/jve.2017.18062

6. Mohammadi Esfarjani S., Salehi M., Ghassemi A. (2017). Effect of the multiple damages and temperature changes on the natural frequency. Journal of Theoretical and Applied Mechanics, Vol. 55, No. 3, pp. 813-822. DOI: 10.15632/jtam-pl.55.3.813

7. Bottai G., Giurgiutiu V. (2005). Simulation of the Lamb wave interaction between piezoelectric wafer active sensors and host structure. SPIE's $12^{\text {th }}$.International Symposium on Smart Structures and Materials and $10^{\text {th }}$.International Symposium on NDE for Health Monitoring and Diagnostics, Sensors and Smart Structures Technologies for Civil, Mechanical, and Aerospace Systems Conference, San Diego, CA, 7-10 March. paper \#5765-29.

http://www.me.sc.edu/research/lamss/pdf/conferences/c1 14_spie2005_5765-29.pdf

8. Wilcox P. D. (1998)..Lamb wave inspection of large structures using permanently attached transducers, $\mathrm{Ph}$. D. Thesis, Imperal college of science,Technology and medicine, university of London, page:19, March. Available; December 2019 at: http://www3.imperial.ac.uk/pls/portallive/docs/1/505497 16.PDF

9. Janarthan B., Mitra M., Mujumdar P. M. (2012). Damage Detection in Stiffened Composite Panels Using Lamb Wave. $6^{\text {th }}$ European Workshop on Structural Health Monitoring, Germany, July 3-6. http://www.ndt.net/article/ewshm2012/papers/we2a4.pdf

10. SunOrc H.,Yi J.,Xu Y.,Wang Y., Qing X. (2019). Identification and Compensation Technique of NonUniform Temperature Field for Lamb Wave-and Multiple Sensors-Based Damage Detection. Sensors, Vol. 19, No. 13, pp. 2930; DOI: 10.3390/s19132930.

11. Sikdar S., Ostachowicz W. (2019). Ultrasonic Lamb wave-based debonding monitoring of advanced 
honeycomb sandwich composite structures, Strain, Vol. 55, No. 1, pp. e12302. DOI: 10.1111/str.12302

12. Giurgiutiu V. (2005). Tuned Lamb wave excitation and detection with piezoelectric wafer active sensors for structural health monitoring..Journal of Intelligent Material Systems and Structures, Vol. 16, pp. 291-306. DOI: 10.1177/1045389X05050106

13. Willberg C., Duczek S., Vivar Perez J. M., Bin Ahmad Z. A. (2015). Simulation Methods for Guided WaveBased Structural Health Monitoring: A Review. Applied Mechanics Reviews, Vol. 67, No. 1, pp. 1-20. DOI: 10.1115/1.4029539

14. Moragaspitiya H. N. P., Thambiratnam D. P., Perera N. J., T..Chan H. T. (2013)..Development of a vibration based method to update axial shortening of vertical load bearing elements in reinforced concrete buildings. Engineering Structures, Vol. 46, pp. 49-61. DOI: 10.1016/j.engstruct.2012.07.010

15. Wenzhong Q. U., Li X. (2009). Finite Element Simulation of Lamb wave with Piezoelectric Transducers for Composite Plate Damage Detection. Advanced Materials Research, Vol. 79-82, pp. 1095-1098. DOI: 10.4028/www.scientific.net/AMR.79-82.1095

16. Nieuwenhuis J.H., Neumann J. J., Greve D.W. Oppenheim I.J. (2005)..Simulation and Testing of Transducers for Lamb Wave Generation, $23^{\text {rd }}$ Conference and Exposition on Structural Dynamics 2005 (IMAC - XXIII), Orlando, Florida, USA. 31 January - 3 February.

https://pdfs.semanticscholar.org/3507/51a92a003f162cf1 12884fd8 940c8d5dfcff.pdf

17. Salamone S., Lanza di Scalea F., Bartoli I. (2009) Temperature effects in Lamb-wave structural health monitoring systems, Health Monitoring of Structural and Biological Systems 2009, edited by Tribikram Kundu,Proc. of SPIE 7295, 72950 DOI:.10.1117/12.815443.

18. Lanza di Scalea F., Salamone S. (2008). Temperature effects in Lamb-wave structural health monitoring systems, The Journal of the Acoustical Society of America, Vol. 124, No. 1, pp. 161-174.. DOI: $10.1121 / 1.2932071$

19. Blaise E., Chang F.-K. (2001). Built-in diagnostics for debonding in sandwich structures under extreme temperatures. In: Proceedings of the $3^{\text {rd }}$ international workshop on structural health monitoring, Stanford University, Stanford, CA, September 12-14, pp. 154-163.

20. Konstantinidis G., Drinkwater B. W., Wilcox P. D (2006). The temperature stability of guided wave structural health monitoring systems, Smart Materials and Structures, Vol. 15, pp. 967-976. DOI: 10.1088/0964-1726/15/4/010

21. Lu Y., Michaels J. E. (2005). A methodology for structural health monitoring with diffuse ultrasonic waves in the presence of temperature variations, Ultrasonics, Vol. 43, No. 9, pp. 717-73..DOI: 10.1016/j.ultras.2005.05.001

22. Michaels J. E., Michaels T. E. (2005). Detection of structural damage from the local temporal coherence of diffuse ultrasonic signals. IEEE Transactions on Ultrasonics, Ferroelectrics, and Frequency Control, Vol 52, No. 10, pp. 1769-1782. DOI:.10.1109/TUFFC.2005. 1561631

23. Dan C., Kudela P., Radzienski M., Ostachowicz W. (2014). Temperature Effects Compensation Strategy for Guided Wave Based Structural Health Monitoring... $6^{\text {th }}$ International Symposium on NDT in Aerospace, Madrid, Spain. 12-14 $4^{\text {th }}$ November. http://www.ndt.net/events/ aeroNDT2014/app/content/Paper/4_Dan.pdf

24. Dhutti A., Gan T.H., Balachandran W., Kanfoud J. (2018)..High temperature performance of ultrasonic guided wave system for structural health monitoring of pipeline. $7^{\text {th }}$ Asia-Pacific Workshop on Structural Health Monitoring, Hong Kong SAR, P.R. China, November 12-15. https://www.ndt.net/article/apwshm2018/papers/17.pdf

25. Han S. J., Palazotto A. N., Leakeas C. L. (2009). FiniteElement Analysis of Lamb Wave Propagat in a Thin Aluminum Plate. Journal of Aerospace Engineering, Vol. 22, No. 2, pp. 185-197..DOI: 10.1061/(ASCE)08931321(2009)22:2(185).

26. Xia Y., Chen B., Weng Sh., Ni Y.Q., Xu Y.L. (2012). Temperature effect on vibration properties of civil structures: a literature review and case studies. Journal of Civil Structural Health Monitoring, Vol. 2, No. 1, pp. 29-46..DOI:10.1007/s13349-011-0015-7

27. Arun.K., Gupta, Mamta.J. (2014). Exponental temperature effect on frequencies of a rectangular plate of non-liner varying thickness:.A quinitic spline.technique. Journal of theoretical and applied mechanics, Vol. 52, No. 1, pp.15-24.

28. Rambabu P., Eswara Prasad N., Kutumbarao V. V., Wanhill R. J. H. (2017). Aluminium Alloys for Aerospace Applications. Chapter 2 of book: Aerospace Materials and Material Technologies, Springer Singapor, Vol. 1: Aerospace Materials, Part I, 29-52, 46 and 47..DOI: 10.1007/978-981-10-2134-3_2

\section{Biographical note}

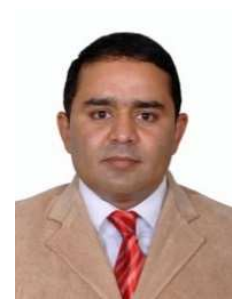

Sattar Mohammadi Esfarjani received his M.Sc. degree in Mechanical Engineering - Applied designing major from the Islamic Azad University of Najafabad in 2016. He has published 12 papers in credible international journals and 2 papers in international conferences. His current research interests include; structural health monitoring and damage detection methods based on vibration and ultrasonic methods, MEMS, NDT, welding, pipeline engineering, composite, temperature changes effect on the vibration methods. 
